\title{
Luciano Tomassini: académico y artífice 1935-2010
}

Recordar en estas páginas a Luciano Tomassini constituye un honor para quien escribe estas líneas. Primero, porque se trata de uno de los grandes teóricos de las relaciones internacionales en América Latina. Segundo, porque Luciano no solo fue uno de los directores de esta revista, sino que contribuyó de manera decisiva a su sobrevivencia en tiempos difíciles. Tercero, porque fue un colega y amigo de muchos años.

Tomassini fue un académico de pensamiento profundo, un teórico agudo y penetrante que cruzaba con frecuencia las fronteras disciplinarias. Siempre siguió los debates de su tiempo, pero eludió sistemáticamente adscribirse a escuelas o corrientes convencionales. El título de su obra póstuma, Rompiendo Códigos, que esperamos con ansiedad pueda publicarse pronto, resume muy bien su ideario. Luciano se alimentó de fuentes intelectuales disciplinarias muy diversas. En una época de fuertes adscripciones teóricas e ideológicas totalizadoras, estructuró un pensamiento propio y singular, haciendo gala de una libertad de espíritu que muy pocos se permitían.

Luciano nació en Ovalle, en el Norte de Chile, en 1935. Un accidente ocurrido en su infancia le obligó a recibir toda su educación escolar en su casa, situada en una pequeña localidad campesina cercana a Santiago, lo que fomentó su hábito de lectura y sin duda su posterior insaciable curiosidad intelectual. Como tantos otros cientistas sociales de su tiempo, Luciano estudió Derecho en la Universidad de Chile, semillero en esa época no solo de vocaciones legales y carreras políticas sino también de las nuevas ciencias sociales que comenzaban a desarrollarse en el país.

Tomassini inició su actividad profesional en un lugar un tanto inesperado a la luz de su carrera posterior. Fue asesor 
legal del Ministerio de Tierras y Colonización, por nada menos que cinco años. Allí tuvo la oportunidad de trabajar bajo las órdenes de dos grandes expertos chilenos: Julio Philippi, internacionalista y Ministro de cuatro carteras incluida la Cancillería, y Francisco Cumplido, constitucionalista y posterior Ministro de Justicia. Luciano combinó su paso por la burocracia estatal con la enseñanza en las Universidades de Chile y Católica de Chile, participando en la fundación de la Escuela de Periodismo de la primera. Su paso por el Ministerio le permitió ejercer su profesión de abogado y también conocer la realidad del Estado chileno, un tema que nunca abandonaría pese a su interés prioritario en las relaciones internacionales. De hecho, retomó este interés de manera sistemática como uno de los fundadores y directivos del Centro de Análisis de Políticas Públicas de la Universidad de Chile y como autor de varios libros sobre la temática del Estado y su siempre pendiente modernización.

Inició su carrera internacional en la División Legal del Banco Interamericano de Desarrollo (BID). Ese gran hombre público y descubridor de talentos que fue Felipe Herrera, fundador y primer Presidente del Banco, lo incorporó posteriormente a su equipo como asesor directo. Hombre de pluma fácil y aguda, Luciano aportó su erudición a numerosas obras y discursos de la nueva entidad, que se transformó efectivamente en un motor para el desarrollo regional. Consciente de la necesidad de complementar su formación, Tomassini interrumpió su carrera en el BID para profundizar sus estudios en instituciones señeras como la London School of Economics and Political Science y el Royal Institute of International Affairs de Londres y la Universidad de Georgetown en Washington.

A comienzos de la década de 1970, Tomassini regresa a vivir a la región, asumiendo la dirección adjunta del Instituto para la Integración de América Latina (INTAL). Establecida en Buenos Aires, esta entidad era a la sazón uno de los mejores think tanks del continente, organizando grandes conferencias, publicando libros y revistas, desarrollando estudios sobre la integración y las relaciones internacionales de la región y convocando a notables académicos de todo el mundo. Fue en ese período que Luciano participó, con la ayuda de una editorial cercana, en un verdadero rescate 
de la revista Estudios Internacionales, afectada primero por la polarización que vivió Chile y esta Universidad en los primeros años de la década y luego por la intervención de la dictadura. Ello permitió que la revista mantuviera su continuidad y, lo que era más importante, su nivel, evitando su instrumentalización y censura.

De regreso en Chile, Tomassini se vinculó a la Comisión Económica para América Latina y el Caribe (CEPAL), al Instituto de Estudios Internacionales de la Universidad de Chile y a otros centros académicos. Hacia los últimos años de la década, proyectó una de sus obras más notables, que dejaría una huella decisiva y muy profunda en el estudio de las relaciones internacionales de la región: el Programa de Estudios Conjuntos sobre las Relaciones Internacionales de América Latina (RIAL). Gracias a un conocimiento inigualable de las potencialidades académicas disponibles en muchos países de la región, una gran perseverancia y una obvia facilidad para relacionarse a la vez con académicos e instituciones donantes, con las luminarias de la disciplina y con investigadores jóvenes, con los grandes centros regionales y con unidades muy modestas, Luciano fue artífice de una red académica que marcó un antes y después en el desarrollo de los estudios internacionales en América Latina. A lo largo de más de diez años, el RIAL organizó grandes encuentros anuales, publicó numerosas obras, contribuyó a abrir una valiosa línea editorial con el Grupo Editor Latinoamericano en Buenos Aires, animó debates intelectuales de gran altura, apoyó activamente a diversas Cancillerías latinoamericanas y patrocinó cursos destinados a la formación de nuevos especialistas. Esta tupida red tejida paso a paso no solo incluyó a académicos, sino que también a diplomáticos y otros especialistas que ocuparon posteriormente cargos de responsabilidad en numerosas Cancillerías de la región. A la luz de sus resultados y de la influencia que lograron los participantes en la red del RIAL, fue quizás una de las mejores inversiones que pudieron hacer las fundaciones e instituciones que la apoyaron. Paradójicamente, la tarea realizada fue tan contundente y llevó un sello tan personal de Luciano que hasta ahora no ha podido ser continuada o replicada, dejando un vacío muy sensible. 
Tomassini se incorporó durante los últimos años a la sede de Chile de la Facultad Latinoamericana de Ciencias Sociales (FLACSO), donde continuó su labor docente y de investigación, manteniendo también su antigua vinculación con la Universidad de Chile. Fue un tiempo de maduración y de cierre personal, en un contexto marcadamente interdisciplinario y de gran libertad intelectual.

La obra de Tomassini habla por sí sola y no corresponde reseñarla aquí. Hombre de teoría y de práctica, tenía claro que toda obra conceptual que no estaba basada en la realidad era irrelevante y que el pensamiento se hacía más necesario en períodos de cambio como los que le tocó vivir. En su trayectoria profesional y académica siempre demostró un compromiso muy profundo con América Latina. Su obra escrita, sus clases, sus conferencias, los proyectos que animó, su vida misma, llevaron la impronta regional. Mas, como buen teórico de las relaciones internacionales, entendió mucho antes que otros que los países latinoamericanos no estaban ni podían aislarse de las tendencias mundiales, que el sistema internacional se regía por reglas que convenía conocer bien y enfrentar de manera realista, que el deber ser no coincidía necesariamente con el ser, y que en un mundo marcado por la interdependencia y una creciente complejidad era más recomendable tratar de entender, antes que ignorar o limitarse a denunciar, los fenómenos globales que nos afectaban directamente. No creía en paradigmas ni en modelos. Buscaba una visión más flexible y liberal acerca de la realidad, en donde ya no se esperara que el ser humano y las instituciones sociales obedecieran necesariamente a un modelo o esencia previa, como lo escribió en un número aniversario de esta revista ${ }^{1}$.

Ningún recuerdo que se haga de su obra y aporte a la academia podría prescindir de su personalidad. Un espíritu libre, abierto y erudito, receloso de los dogmas, escéptico de los radicalismos y del pensamiento utópico, marcado por una algo sorprendente modestia, una permanente discreción y una cálida sociabilidad que compartía con su admirable mujer, Ana

1 Luciano Tomassini, «El mundo y la sociedad en la era de la globalización», Estudios Internacionales, N 154, julio-septiembre 2006, pág. 26. 
- O B I T U A R I O •

María Aguirre, y sus hijas Ana María y Pía. Todos quienes hemos incursionado en el complejo mundo de la teoría o la práctica de las relaciones internacionales en América Latina tenemos mucho que agradecerle.

Alberto van Klaveren 